\title{
What is the Probability of a Patient Presenting a Pleural Effusion due to Tuberculosis?
}

\author{
Denise Duprat Neves ${ }^{1}$, Ricardo Marques Dias ${ }^{1}$, \\ Antônio José Ledo Alves da Cunha ${ }^{2}$ and \\ Paulo César Amorim Preza ${ }^{1}$
}

\author{
University of Rio de Janeiro ${ }^{1}$; Federal University of do \\ Rio de Janeiro ${ }^{2}$, Rio de Janeiro, RJ, Brazil
}

Introduction: In Rio de Janeiro, in almost half of the cases of pleural tuberculosis (PT) treatment begins without substantiation of diagnosis. We examined variables associated with this disease. Method: We studied 215 consecutive patients; 104 had tuberculosis (TB) and 111 did not (NTB): 41 neoplasms, 29 transudates, 28 para-pneumonic and 13 other etiologies. Clinical and laboratory variables were assessed in a combined manner using likelihood ratios (LR) and Bayes' theorem to determine the probability of PT. Results: Among the variables examined, adenosine deaminase (ADA) levels, lymphocyte cell percentage, protein and age were the best indicators for the diagnosis of PT. Association of ADA with any of the other variables led to a LR+ higher than 10 and a LRlower than 0.1, indicating the presence or absence of PT, with an individual probability of more than $90 \%$ or of less than $10 \%$ considering that there was a $50 \%$ initial probability associated with the presence of PT. Conclusions: Since ADA is highly sensitive, we can practically exclude TB as the cause of effusion when there are low ADA values. However, to confirm the possibility of TB we recommend that other variables, such as prevalence of lymphocytes (higher than $90 \%$ ), and high protein levels (more than $4 \mathrm{~g} / \mathrm{dL}$ ); low age (less than 45 years) also should be considered. Key Words: Bayes' Theorem, tuberculosis, pleural effusion, adenosine deaminase and diagnosis.

The gold standard for tuberculosis diagnosis is bacterial culture with lineage identification. This method may require from four to eight weeks and in cases of pleural involvement has only a reasonable sensitivity. Tuberculosis diagnosis based on positive fluid culture is made in about one third of the cases and less than two thirds are positive in the culture of pleural specimens $[1,2]$. In areas of high tuberculosis prevalence, the finding, of a granuloma, especially with caseation necrosis, is an accepted criterion for the diagnosis of tuberculosis [1-4]. In this case, sensitivity is systematically higher than a positive culture, however

Received on 22 March 2004; revised 12 August 2004. Address for correspondence: Dr. Denise Duprat Neves. Rua Mariz e Barros 775, Hospital Universitário Gaffrée e Guinle, DEMESP, Pneumologia. Tijuca, Rio de Janeiro. Brasil. Zip code: 20270-004. Phone: 5502125697610 - r 304. E-mail: dduprat@unirio.br

The Brazilian Journal of Infectious Diseases 2004;8(4):311-318 (C) 2004 by The Brazilian Journal of Infectious Diseases and Contexto Publishing. All rights reserved. it does not exceed $85 \%$, even under ideal conditions [5].

In the city of Rio de Janeiro, more than $40 \%$ of the pleural effusions [6,7] are related to tuberculosis and in about half of the notified cases the diagnosis is not confirmed by accepted criteria [8]. In view of the high frequency of tuberculosis related pleural effusions and the difficulty of confirming diagnosis, studies of factors that could contribute to the probability of diagnosis are needed. The main objective of this study was to assess the contribution of clinical, radiological and laboratory variables to the probability of diagnosis of pleural tuberculosis.

\section{Materials and Methods}

We investigated consecutive patients submitted to routine tests for diagnostic investigation of pleural effusion at a general hospital: "Hospital Universitário Gaffrée e Guinle” of Rio de Janeiro University, Brazil. 
The tuberculosis group (TB) of 104 patients comprised cases complying with one or more of the following criteria: (i) presence of bacilli in the direct test (AFB) or in the culture of fluid or pleural specimens; (ii) presence of granuloma with caseation necrosis, or without necrosis, in the pleural specimen, whenever it is associated with bacteriologically proven tuberculosis at another site, or there is no evidence of other granulomatous diseases. The non-tuberculosis group (NTB), with 111 cases, included 29 patients with transudates (TRANS) [9] and 82 with exudates, 41 of which were derived from neoplasms (NEO), 7 from lymphomas and 34 from metastases; 28 parapneumonic (PPN), including 12 simple PPN and 16 complicated, and an additional 13 with other diagnoses, defined according to the accepted medical criteria $[2,10]$.

Gender, age and duration of disease data were recorded based on interviews. The radiological findings concerning the site, volume and presence of lesions associated with the effusion were analyzed by a pulmonologist on the day of the thoracocenthesis.

Protein, lactic deshydrogenase, bacteriological exam and cytometry of the pleural fluid were carried out as is done routinely, and the cutaneous test with PPD was assessed. All laboratory tests were performed by technicians unaware of the diagnosis, and were done in accordance with published recommendations [2,7,1113]. Dosage of ADA in the pleural fluid was assayed in duplicate, according to the Giusti technique [14].

Patients were excluded when (1) dosing of ADA was not possible (due to a long period of storage, accidental unfreezing, clouding of the fluid, when the control test level was very high or when there was a larger than permissible difference between the duplicate readings), (2) there was no confirmed diagnosis, or (3) patients were previously included in the study.

Analysis of diagnostic test data was made with $2 \times 2$ contingency tables, permitting calculations of likelihood ratios (LR) (Figure 1). The transformation of continuous variables into dichotomous ones was performed after identification of the best cut off point based on the received operating characteristics (ROC) curve [15,16]. The LR calculated for each variable at different points was used along with Bayes' theorem for post-test probability calculations. The post-test odds of there being a disease was calculated by multiplying the pre-test odds by the LR value $[15,17,18]$, considering the pre-test odds as the prevalence of the disease, as follows:

Pre-test odds $=$ prevalence $/(1-$ prevalence $)$

Post-test odds $=$ pre-test odds $\mathrm{x}$ LR

Post-test probability $=$ Post-test odds $/(1+$ Posttest odds).

Although calculation with formulas is not a difficult task, it can be tedious. A nomogram (Figure 2), proposed by Fagan [19], simplifies these conversions, proceeding directly from the pre-test probability, in the first column to the post-test probability in the third column, with a straight line that crosses the estimated LR in the middle column.

This project was approved by the Ethics Committee of the HUGG, in accordance with resolution 196/96 of the Health Ministry. There was no conflict of interests or outside source of support for this project.

\section{Results}

The initial sample comprised 294 pleural effusions successively obtained by needle aspiration, according to standard procedures. Forty-two patients were excluded due to the impossibility of dosing ADA, 5 because they had formerly been included and 32 because the diagnosis was not confirmed (17 probably had tuberculosis).

The confirmation of the diagnosis of tuberculosis was mainly made with the detection of a granuloma ( $95 \%$ of the cases); in $74 \%$ caseation necrosis was found. Cultures were positive for the Koch bacillus in $4.8 \%$ of the cases, when the histopathological test was not specific. AFB and positive culture of the pleural fluid was found in less than $10 \%$, while culture of the specimen was positive in $58 \%$ of the cases examined.

To discriminate pleural tuberculosis from other causes of effusion, we selected variables that had high isolated performance, such as: age, protein dosage, percentage of lymphocytes and ADA activity. These 
variables presented consistent usefulness, with significant differences from the central measures between groups, high values in the area below the ROC curve (greater than 0.7), good accuracy (above 70\%) and a high odds ratio (above 5).

Diagnostic tests may be interpreted as a function of various discriminatory values (Table 1). Post-test probability can be calculated by associating variables that increase the certainty of diagnosis. The association of ADA with any of the other variables in Table 1 increased the probability of disease from $50 \%$ to over 90\%. Using Bayes' theorem, considering the pre-test odds of 1:1 and all variables with values above their best discriminatory value (ADA with $\mathrm{LR}+=5.56$, age with $\mathrm{LR}+=2.11$, lymphocytes with $\mathrm{LR}+=2.09$ and protein with $\mathrm{LR}+=1.96$ ), the probability of tuberculosis increased to $98 \%$. If all values were below the best discriminatory values (ADA with $L R=0.06$, age with LR $-=0.3$, lymphocyte with LR- $=0.2$ and protein with $\mathrm{LR}-=0.26$ ), the probability of tuberculosis would be less than $1 \%$. The following equations demonstrate these calculations:

Post- test odds $=1.0 \times 5.6 \times 2.1 \times 2.09 \times 1.6$ and, therefore

Probability post-positive tests $=48.6 /(48.6+1)$. Post test odds $=1 \times 0.06 \times 0.3 \times 0.2 \times 0.26$ and, therefore

Probability post-negative tests $=0.0009 /(0.0009+1)$.

These calculations were done using data from 196 cases (which had data on all 4 variables), using only the discriminatory value of highest accuracy and the posttest probability value greater than 0.5 as being indicative of tuberculosis. We obtained the following values for sensitivity and specificity: for two variables, ADA and lymphocytes, it was $94.9 \%$ (95\%CI: $90 \%-98 \%$ ) and $84.5 \%$ (95\%CI: $70 \%-88 \%$ ); for three variables, associating these with a protein, it was $92.9 \%(95 \% \mathrm{CI}$ : $88 \%-96 \%$ ) and $90.7 \%$ (95\%CI: 85\%-94\%); and for four variables, adding age, it was $90.9 \%$ (95\% CI: 86\%94\%) and 93.8\% (95\%CI: 89\%-97\%).

When there is inclusion of more variables, there is an increment of specificity, but a decrease in sensitivity
(Figure 3). The kappa test was used to measure the agreement between the diagnosis reached by the equation and the one set by the gold standard. For two variables, it was $79.6 \%$ (95\%CI: $69 \%-86 \%$ ), for three variables it was $83.7 \%$ (95\%CI: $73 \%-91 \%$ ) and for four variables it was $84.7 \%$ (95\% CI: $74 \%-91 \%$ ).

\section{Discussion}

This study substantiates the difficulty of ascertaining the diagnosis of pleural tuberculosis according to the recommended criteria, such as the gold standard, especially without a pleural biopsy. Nearly all (95\%) of the diagnoses were reached by typical histopathological exams of the pleural specimen. In only $11 \%$ of the patients diagnosis was not possible, and in $53 \%$ of these tuberculosis was the probable cause of effusion.

The starting point for any diagnosis is suspicion based on clinical history, disease prevalence in the region or other tests. Using this information, the clinician elaborates diagnostic hypotheses that will or not be confirmed by complementary exams. The suspicion of the presence of a given disease is defined as pre-test probability $[15,18]$.

The difficulty of estimating such probabilities has been one of the constraints for the use of this methodology in medical practice. This problem has been minimized by the recommendation of using prevalence of the disease in each region as a pre-test probability. This approach also allows us to regionalize the predictive rule.

In our sample, the prevalence of tuberculosis was $48 \%$, similar to that of other studies, especially those carried out in public health units in Rio de Janeiro and São Paulo $[6,7,20]$. That is why we suggest a pre-test probability of $50 \%$. We know that diagnostic tests are more useful when the pre-test probability ranges between 30 and $70 \%$, that is to say when we are not quite sure of the presence (or not) of the disease.

The likelihood ratio expresses how much more probable it is to find a positive test in persons that have the disease, as opposed to those that do not have it. It has been viewed as the best measure of the usefulness 
Table 1. Performance of variables and the best efficiency achieved using different discriminatory values for the diagnosis of tuberculosis

\begin{tabular}{|c|c|c|c|c|c|c|c|c|c|}
\hline & \multicolumn{2}{|c|}{$\mathbf{N}$} & \multirow{2}{*}{ Value } & \multirow{2}{*}{ Se } & \multirow{2}{*}{ Sp } & \multirow{2}{*}{ LR+ } & \multirow{2}{*}{ LR- } & \multirow{2}{*}{ PV+ } & \multirow{2}{*}{ PV- } \\
\hline & TB & NTB & & & & & & & \\
\hline \multirow[t]{9}{*}{ ADA } & 104 & 111 & $>15$ & 100 & 41 & 1.71 & 0.00 & 61 & 100 \\
\hline & & & $>26$ & 99 & 72 & 3.55 & 0.01 & 77 & 99 \\
\hline & & & $>30$ & 98 & 76 & 4.19 & 0.03 & 80 & 98 \\
\hline & & & $>39^{*}$ & 95 & 83 & 5.56 & 0.06 & 84 & 95 \\
\hline & & & $>45$ & 91 & 85 & 5.90 & 0.11 & 85 & 91 \\
\hline & & & $>60$ & 83 & 87 & 6.12 & 0.20 & 85 & 84 \\
\hline & & & $>80$ & 53 & 90 & 5.34 & 0.52 & 83 & 67 \\
\hline & & & $>100$ & 27 & 94 & 4.27 & 0.78 & 80 & 58 \\
\hline & & & $>140$ & 4 & 97 & 1.42 & 0.99 & 57 & 52 \\
\hline \multirow[t]{7}{*}{ Age } & 104 & 111 & $\leq 20$ & 14 & 95 & 2.49 & 0.91 & 70 & 54 \\
\hline & & & $\leq 30$ & 54 & 81 & 2.85 & 0.57 & 73 & 65 \\
\hline & & & $\leq 40$ & 73 & 68 & 2.25 & 0.40 & 68 & 73 \\
\hline & & & $\leq 45^{*}$ & 82 & 61 & 2.11 & 0.30 & 66 & 78 \\
\hline & & & $\leq 50$ & 86 & 51 & 1.76 & 0.28 & 62 & 79 \\
\hline & & & $\leq 60$ & 94 & 32 & 1.38 & 0.18 & 56 & 85 \\
\hline & & & $\leq 75$ & 99 & 6 & 1.06 & 0.15 & 50 & 88 \\
\hline \multirow[t]{6}{*}{ Lymphocytes } & 103 & 109 & $>40$ & 100 & 30 & 1.43 & 0.00 & 58 & 100 \\
\hline & & & $>60$ & 95 & 35 & 1.46 & 0.14 & 58 & 89 \\
\hline & & & $>72$ & 90 & 43 & 1.59 & 0.23 & 60 & 83 \\
\hline & & & $>81^{*}$ & 88 & 58 & 2.09 & 0.20 & 66 & 84 \\
\hline & & & $>90$ & 59 & 80 & 2.93 & 0.51 & 74 & 67 \\
\hline & & & $>98$ & 28 & 91 & 2.11 & 0.99 & 67 & 52 \\
\hline \multirow[t]{6}{*}{ Protein } & 104 & 110 & $>3.0$ & 99 & 31 & 1.43 & 0.03 & 58 & 97 \\
\hline & & & $>3.5$ & 95 & 38 & 1.54 & 0.13 & 59 & 89 \\
\hline & & & $>4.1^{*}$ & 86 & 56 & 1.96 & 0.26 & 65 & 81 \\
\hline & & & $>4.5$ & 65 & 70 & 2.18 & 0.49 & 67 & 68 \\
\hline & & & $>5$ & 32 & 83 & 1.84 & 0.83 & 64 & 56 \\
\hline & & & $>6$ & 3 & 95 & 0.53 & 1.03 & 33 & 51 \\
\hline
\end{tabular}

$\mathrm{ADA}=$ adenosine deaminase, $\mathrm{n}=$ number of cases, $\mathrm{TB}=$ tuberculosis, $\mathrm{NTB}=$ non tuberculosis, $\mathrm{Se}=$ sensibility, $\mathrm{Sp}=$ specificity, $\mathrm{LR}=$ likelihood ratio, $\mathrm{PV}=$ predictive value,$+=$ positive, $-=$ =negative and $*=$ cut off of best accuracy. 
of a diagnostic test, indicating the probability of the presence or the absence of disease in view of the result of one or more tests [15,21]. Its use, associated with the Bayesian methodology, permits us to evaluate the association of variables in a simple way. Isolated or associated tests with LR+ greater than 10 or lower than 0.1 , practically confirms the presence or absence of disease [22], which in our case was pleural tuberculosis. In our study, we can increase the probability of the disease from $50 \%$ to over $90 \%$, or decrease it to less than $10 \%$ (Figure 2).

Bayes' theorem is expressed by a formula showing how an existing belief (the diagnostic hypothesis) is modified as a function of new information (diagnostic test results), up-dating this probability up to the certainty of diagnosis [18,23]. Such a probability will change when we use the result of diagnostic tests, herein expressed by the likelihood ratio (LR).

Likelihood ratios may be used sequentially, that is to say the post-test probability (after performance of a test) may be used as a pre-test probability of another, or more easily combined in the formula: post-test odds $=$ pre-test odds $\mathrm{x}$ LR1 $\mathrm{x}$ LR2 $\mathrm{x} . . . \mathrm{x}$ LRn.

As isolated diagnostic tests, age, dosage of protein, the percentage of lymphocytes, in addition to ADA activity, show consistent usefulness to differentiate tuberculosis from the remaining causes of effusion [11, 20]. Other authors have also suggested the use of these variables in different combinations [20,24-26].

Of the various variables, ADA gave the highest LR; when levels were above 39U/L, the probability of pleural tuberculosis increased from $50 \%$ to $85 \%$. When the ADA values were lower than this level, the probability of pleural tuberculosis was reduced to less than $6 \%$. It is noteworthy that higher values of enzyme activity were not correlated with higher LR. The value of LR was maximal between 60U/L and 90U/L, but then it dropped, and with values higher than $120 \mathrm{U} / \mathrm{L}$ the LR+ was lower than 1.5 . When a very high value of ADA is observed in the pleural fluid, we should consider the possibility of a false positive result, mainly due to empyema and lymphoma.

Given the pre-test probability of $50 \%$, the association of ADA results higher than 39U/L and lymphocytes counts greater than $80 \%$; the diagnosis of pleural tuberculosis is practically confirmed with a probability greater than $92 \%$. The LR+ for patients under 45 years of age was around 2, similar to that observed for lymphocytes counts higher than $80 \%$, and similar to the results reached in another Brazilian study [20]. In patients under 25 years of age, the $\mathrm{LR}+$ is near 3 , increasing the odds of diagnosis. The association of ADA with lymphocyte counts, or protein levels, or age, provides us with an LR higher than 10, increasing the post-test probability up to more than $90 \%$. Accuracy of diagnosis of pleural tuberculosis increases when we take into account a greater number of variables, due to the increase in specificity. The probability of disease in patients with ADA, lymphocytes and protein higher than the discriminatory values, as suggested by the ROC curve, is $96 \%$. The combination of four variables, these ones plus age, leads to a $98 \%$ probability of tuberculosis.

Association of the three criteria (age, lymphocytes and protein), without ADA, gives an LR+ of 8.6 and an LR- of 0.016, with a performance similar to that found with ADA alone. Therefore, numerous combinations may be used, once we know the values of the LRs.

Results of most complementary exams do not permit a definitive conclusion concerning the presence or absence of a given disease. They only increase or decrease to varying degrees our confidence in a given diagnosis. Although such informal, intuitive procedures have proven to be rather accurate, this can vary among professionals. Using the Bayesian methodology we could quantify this uncertainty [18]. For any disease, there is a particular probability of its presence that exempts additional tests for confirmation of diagnosis, just as there is another probability in which its presence is excluded and other tests are dismissed. If the probability varies between these two, additional diagnostic tests are recommended. Once the limits of investigating or treating have been decided, patient management becomes easier.

In practice, the usefulness of this methodology therefore rests on what probability of disease we shall consider sufficient to diagnose a given case as 
Figure 1. Contingency table for the calculation of diagnostic test properties

\begin{tabular}{|c|c|c|c|}
\hline \multirow{2}{*}{$\begin{array}{l}\text { Test } \\
\text { Result }\end{array}$} & \multicolumn{2}{|c|}{ Diagnosis } & \\
\hline & ill & t ill & total \\
\hline positive & a & b & $a+b$ \\
\hline negative & C & d & $c+d$ \\
\hline total & $a+c$ & $b+d$ & \\
\hline
\end{tabular}

Where:

$\begin{array}{ll}a=\text { true positive } & \text { Sensibility }(\mathrm{Se})=\mathrm{a} /(\mathrm{a}+\mathrm{c}) \\ \mathrm{b}=\text { false positive } & \text { Specificity }(\mathrm{Sp})=\mathrm{d} /(\mathrm{b}+\mathrm{d}) \\ \mathrm{c}=\text { false negative } & \text { Likelihood ratio for a positive test }=\mathrm{Se} /(1-\mathrm{Sp}) \\ \mathrm{d}=\text { true negative } & \text { Likelihood ratio for a negative test }=(1-\mathrm{Se}) / \mathrm{Sp}\end{array}$

Figure 2. Fagan's nomogram

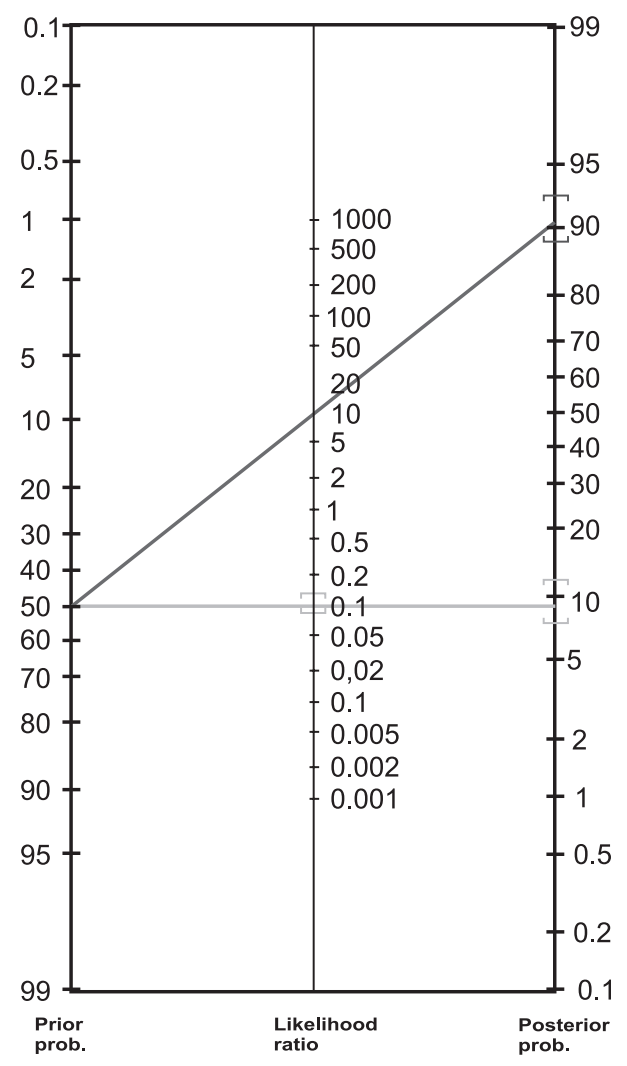

In the example the blue line shows the post-test probability calculation (of approximately 90\%), using a test with LR $+=10$, and starting from a prevalence of $50 \%$. The red line shows the calculation using a negative value (LR- $=0.1)$ In this case, the probability of the presence of the disease is lower than $10 \%$. Brackets around the estimated point represent the limits of the confidence interval at $95 \%$ obtained in this study. 
Figure 3. Correct classification of the cases with different associations of variables

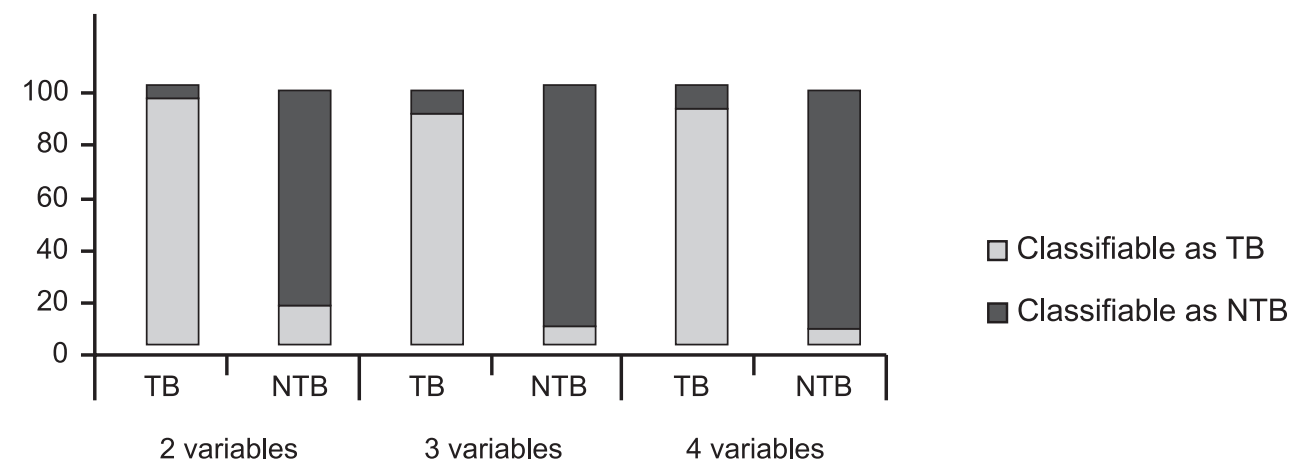

Note that with the increase in the number of variables included in the combination, there is a decrease in the identification of the cases of pleural tuberculosis, but as a counter-part there is an increase in the certainty of diagnosis.

pleural tuberculosis and when to discard this diagnosis. These probabilities are not yet well defined, though they are important even to evaluate if the available tests are sufficient or insufficient for proper clinical conduct.

Some authors are in favor of initiating tuberculosis treatment irrespective of a diagnostic confirmation by biopsy, in regions of high prevalence of tuberculosis (TB), if a patient presents with high ADA associated with other clinical or laboratory parameters of the disease $[4,7,20,27]$. We suggest using the following strategy: if ADA activity is low we can practically exclude the diagnosis of TB, because of its high sensitivity. However, if ADA values are high, we should use the results of other variables to help us make a decision, in order to increase specificity, which in turn would increase the certainty that the case is indeed TB.

Such rules of prediction must be validated with other samples, to determine how many and which association of variables gives the best performance for a given population. We do not downgrade the importance of bacteriological and histopathological procedures. The use of a simple test, as a substitute for a more elaborate, expensive and invasive one, although the latter is more exact, is often done with the understanding that this may entail a certain risk of incorrect diagnosis. However, the probability calculation of the presence of pleural tuberculosis may be a useful alternative to diagnosis based only on the physician's intuition. In our region, pleural tuberculosis must always be included as the main diagnostic hypothesis in cases of pleural effusion. Tuberculosis is responsible for up to half of the cases of pleural effusion, may evolve to local or distant complications and can be efficiently treated with few severe side effects.

\section{References}

1. Martins S.A.S., Gerhardt Filho G., Santiago A.C., et al. Derrame pleural tuberculoso. Tisio-Pneu 1977;IX(1):133-66.

2. Light R.W. Pleural Diseases. 3rd ed. Philadelphia: Lea \& Febiger; 1995.

3. Ferrer J., Hamm H., Light R.W. Pleural tuberculosis. Eur Respir J 1997; 10:942-7.

4. Valdes L., Alvarez D., San Jose E., et al. Tuberculous pleurisy: a study of 254 patients. Arch Intern Med 1998; 158(18):2017-21.

5. Follador E.C.R., Pimentel M., Barbas C.S.V., et al. Derrame pleural tuberculoso: avaliacao clinica e laboratorial. Rev Hosp Clin Fac Med Sao Paulo 1991;46(4):176-9.

6. Neves D.D. O valor da adenosina desaminase no diagnóstico diferencial dos derrames pleurais [Tese de Mestrado]. Rio de Janeiro: Universidade Federal do Rio de Janeiro; 1992. 
7. Silva Jr C.T. Adenosina desaminase "versus" histopatológico pleural: avaliação da importância da toracocentese isolada para o diagnóstico da tuberculose pleural [Tese de doutorado]. Niterói (RJ): Universidade Federal Fluminense; 2000.

8. Soares E.C.C. Sistema Nacional de Agravos de Notificação (SINAN): Informações sobre as notificações de tuberculose obtidas na SMS-RJ. In. Rio de Janeiro: Secretaria Municipal de Saúde; 2002.

9. Light R.W., Macgregor M.I., Luchsinger P.C., Ball W,C, Jr. Pleural effusions: The diagnosis separation of transudates and exudates. Am Int Med 1972;77(4):507-13.

10. Marel M., Stastny B., Milinová L., et al. Diagnosis of pleural effusions. Experience with clinical studies, 1986 to 1990 . Chest 1995; $107: 1598-603$.

11. Neves D.D., Dias R.M., Cunha A.J.L.A., Chibante A.M.S. Rendimento de variáveis clínicas, radiológicas e laboratoriais para o diagnóstico da tuberculose pleural. J Bras Pneumol 2004;30(4):319-26.

12. Chalhoub M., Arruda S., Fidélis R., et al. Análise da biópsia pleural em 107 pacientes sem líquido pleural. J Pneumol 1999;25(3):141-6.

13. Hirsch A., Ruffie P., Nebut M., et al. Pleural effusion: laboratory tests in 300 cases. Thorax 1979;34:106-12.

14. Giusti G. Adenosine deaminase. In: Bergmeyer H.U., editor. Methods of Enzymatic Analysis. New York: Academic Press; 1974. p. 1093-9.

15. Fletcher R.H., Fletcher S.W., Wagner E.H. Epidemiologia Clínica: elementos essenciais. 3 ed. Porto Alegre: Artes Médicas; 1996.

16. Altman D.G,. Bland M. Diagnostic tests 3: receiver operating characteristic plots. Br Med J 1994;309:188.

17. Altman D.G., Bland J.M. Statistics Notes: Diagnostic tests 1: sensitivity and specificity. Br Med J 1994;308:1552.

18. Knottnerus J.A., van Weel C., Muris J.W.M. Evidence base of clinical diagnosis. Evaluation of diagnostic procedures. Br Med J 2002;324:477-80.

19. Fagan T.J. Nomogram for Bayes' theorem. N Engl J Med 1975;293:257-61.

20. Fiuza de Melo F.A. Atividade da adenosina desaminase (ADA) isolada e combinada a outras variáveis no diagnóstico da tuberculose pleural e sua aplicabilidade em infectados pelo vírus da imunodeficiência humana (VIH) [Doutorado em Medicina]. São Paulo: Universidade Federal de São Paulo; 1997.

21. Greenhalgh T. How to read a paper: Papers that report diagnostic or screening tests. $\mathrm{Br}$ Med J 1997;315:540-543.

22. Jaeschke R., Guyatt G., Sackett D.L. Users' guides to the medical literature. III. How to use an article about a diagnostic test. B. What were the results and will they help me in caring for my patients? JAMA 1994;271(9):703-7.
23. Spiegelhalter D.J., Myles J.P., Jones D.R., Abrams K.R. An introduction to bayesian methods in health technology assessment. Br Med J 1999;319:508-512.

24. I Consenso Brasileiro de Tuberculose. Sociedade Brasileira de Pneumologia e Tisiologia. J Pneumol 1997;23(6):281342.

25. Lee Y.C.G., Rogers J., Rodriguez R.M., et al. Adenosine deaminase levels in nontuberculous lymphocitic pleural effusions. Chest 2001;120(2):356-61.

26. Oliveira H.G., Rossatto E.R., Prolla J.C. Pleural fluid adenosine deaminase and lymphocyte proportion: clinical usefulness in the diagnosis of tuberculosis. Cytopathology 1994;5(1):27-32.

27. Valdes L., Alvarez D., San José E., et al. Value of adenosine deaminase in the diagnosis of tuberculous pleural effusions in young patients in a region of high prevalence of tuberculosis. Thorax 1995;50:600-3. 